Original article

\title{
Do family planning advice and maternal health care utilization changes course in contraception usage? A study based on Bihar, India
}

\author{
Pradeep Kumar*, Himani Sharma, Donald R. Mawkhlieng \\ Department of Mathematical Demography \& Statistics, International Institute for Population Sciences, Mumbai, Maharashtra, 400088, India
}

\section{A R T I C L E I N F O}

\section{Keywords:}

Maternal health

Family planning

Advice

\begin{abstract}
A B S T R A C T
Objective: Population growth has been a part of India's concern since a long time which resulted into formulation of many policies and programme. Expansion of access to contraception and reduction of the unmet need for family planning are key components to improve reproductive health. The study aims to access the effect of family planning advice and maternal health care utilization on contraceptive usage in Bihar.

Methods: The study used the data from the National Family Health Survey, round 4, (2015-16). Bivariate and multivariate analyses have been employed to examine the factors affecting the contraceptive use among women in Bihar.

Results: Majority of the women preferred modern contraceptive methods with female sterilization being the most common among all. More than half of married women received advice on family planning methods but were found to be inconsistent in influencing the contraceptive use. Women who have received proper maternal health care were found to have more likelihood in adopting family planning methods. Age, residence, religion and wealth index are the significant predictors of contraception use. Age and wealth of the women depicted a positive relationship with the contraception use. Interestingly, results suggest that advice on family planning didn't have much effect on birth control in Bihar.

Conclusion: The study concludes that more needs to be done to support the need for adequate maternal health care utilization to increase the use of contraception. Efforts are required to ensure that currently married women across socio-economic backgrounds have an equal opportunity to received maternal health services.
\end{abstract}

\section{Introduction}

The growth of Population has long been a concern of any country and India has an extensive history of explicit population policy. The increase of access over contraception and reduction of the unmet need for Family Planning (FP) are vital components to improve reproductive health. Literature has highlighted numerous benefits of FP, for instance, reduction in fertility and unwanted pregnancies ${ }^{1}$; infant and maternal death, ${ }^{2,3}$ education and economic benefits. ${ }^{4}$ More importantly, FP is one aspect of the targets around universal access to sexual and reproductive health found in the SDGs (3.7 and 5.6). ${ }^{5} \mathrm{FP}$ in India is a part of one's personal choice and could only encourage not force to implement. Hence, the government's role in FP is to promote it through various programme emphasizing the benefits of small family concepts. Most of the public health care providers have FP services to cater the needs of married couples beginning from counseling to its usage.

The continuum of care including antenatal, delivery and the postnatal care is critically important in high focus states of India, like Bihar.
Both mothers and babies are vulnerable to a range of health risks resulting in high maternal and neonatal mortality. FP advice is an essential component in the continuum of care and also the key element to improving health behavior of the women and health-care seeking during the antenatal, delivery and post-delivery stage. ${ }^{6}$ The information provided during the antenatal care (ANC) enables women and their family members to later take care of their newborn, adopt healthy behaviors and to identify and act on medical emergencies that may arise during antenatal, natal and post-natal care (PNC) periods. ${ }^{7}$ Taking advice on suitable FP methods ensures spacing between children. It may provide to preventing unwanted pregnancies. Although, the earlier research report that advice on family planning has a changing role in ANC service utilization and skilled birth attendance (SBA) in the developing country contexts. ${ }^{8}$ Advice on family planning is the part of the standard practice of care for women who have just given birth. Demand for contraception methods is potentially high after delivery, and birth spacing plays a critical role in improving $\mathrm{MCH} .{ }^{3,9}$ Post-integration most recent multi-country studies based on Demographic and Health Survey

\footnotetext{
${ }^{*}$ Corresponding author.

E-mail addresses: pradeepiips@yahoo.com (P. Kumar), himani.sharma446@gmail.com (H. Sharma), mawdonric@gmail.com (D.R. Mawkhlieng).
} 


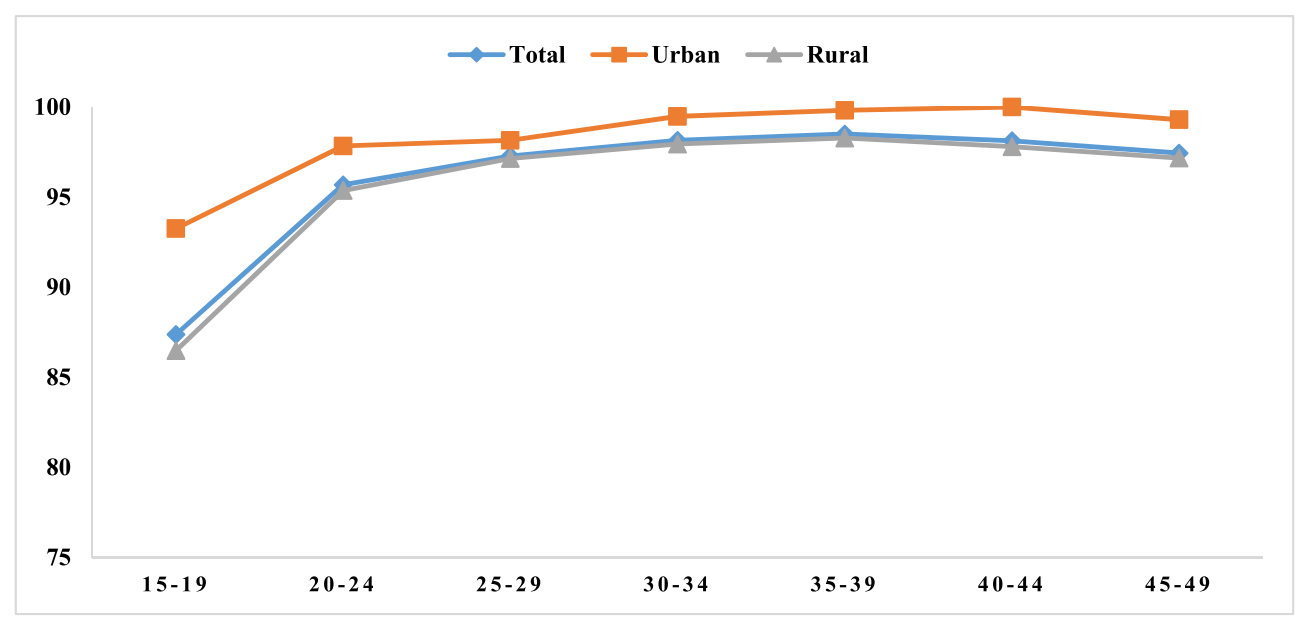

Fig. 1. Knowledge of contraceptive methods among women age 15-49 in Bihar, 2015-16.

data show a positive relation between $\mathrm{MCH}$ service and use of family planning methods. ${ }^{10,11}$ This improvement is not demonstrated by exogenous variables. ${ }^{12}$ Providing the ANC services is the opportunities to reach the women who would be the main target of Family Planning services. This has been the motive behind standard strategies using antenatal care as an approaching period for the delivery of reproductive health services, including FP services. ${ }^{13}$ Some studies have shown that there is a tendency among health workers for promoting ANC and institutional delivery only while FP advice is minimal. ${ }^{14,15}$ An earlier study suggests that an ANC package including FP advice significantly increased the quality of care. ${ }^{16}$ In the South Asia region ${ }^{17,18}$ particularly in India, studies show that PNC is limited to inequality in service utilization. ${ }^{19,20}$ Previous studies examining the value of integration have mixed findings. A study based on a randomized control trial on educational interventions for contraceptive use reveals that women who received postpartum counseling on family planning with repeated contacts were more influenced to use FP methods. ${ }^{21}$ Bihar is the third most populous and one of the least developed states with a long history of high fertility in India and having low socio-economic status. It is also a highly focused state with 10 high priority districts out of 38 districts in 184 high priority districts (by the government of India) in India under NRHM. Although NRHM was launched in 2005 with an integration plan, there is a dearth of literature particularly in Bihar to identify the role of maternal and child health care in an increase in the use of contraceptive and decrease in the unmet need for family planning. Therefore, the present study is an attempt to study the answer to the following questions: Does Family planning advice increase the use of contraception? Or does maternal health care utilization play any role in the prevalence of contraception use? This study hypothesizes that family planning advice is the key factor to increase the use of contraceptives and maternal health care utilization play an important role in the use of contraception. The study intends to an analysis by showing the prevalence of contraceptive use in Bihar, India. The overall aim of this study is to examine the effect of family planning advice and use of maternal health care utilization on contraceptive use in Bihar, India.

\section{Methods}

The study used the recently released data from National Family Health Survey (NFHS) round 4, (2015-16). NFHS data provides information on population, health, nutrition, abortion, sexual behavior, HIV/AIDS knowledge, attitudes, behavior, and domestic violence for India as well as each state and union territory and district for India, conducted under the stewardship of the Ministry of Health and Family Welfare (MoHFW) of India. This survey covered all 35 states and union territories and also first time covered all 640 districts in order to monitor provide the corrective measure on health system. NFHS uses stratified two-stage sampling procedure for the selection of the sample and certain specific set of questions were asked using standard questionnaires with the consent of the respondents. The present study utilizes data for Bihar only, with the sample of 45,812 and restrict for currently married women with the sample 35,373 .

Knowledge of contraceptive use is defined as the currently married women aged 15-49 who know at least one method of contraception. ${ }^{22}$ The outcome variable in the present study is the Current use of contraception. The information was obtained from currently married women regarding the use of family planning methods by asking them the question "Are you currently doing something or using any method to delay or avoid getting pregnant? If the answer is yes, then further asked name of the method. Modern method is defined as the women were using Diaphragm, Female condom, Lactational amenorrhea, Injections, IUD, Pill, Female sterilization whereas traditional methods are Rhythm/periodic abstinence and withdrawal. Total current use of contraceptives includes the current use of traditional and modern methods of family planning; limiting methods include male and female sterilization whereas rest of the methods come under spacing.

Age, any Ante natal care (ANC), place of delivery, post-natal care (PNC), advice on family planning, place of residence, education status, caste, religion and wealth index are the predictors for this study. We created a proxy variable for maternal health care utilization using variables like utilization of ANC, institutional delivery and postnatal care within two weeks. If the women received any ANC and has gone for the institutional delivery and received postnatal care within two weeks, it is as coded "Yes" otherwise it is coded as "No". Bivariate as well as multivariate analysis has been used to fulfill the specific objectives of the study. For the bivariate analysis, cross-tabulation and chi-square test has been used to examine the significant association between use of contraceptives and different socio-economic and demographic predictors. Furthermore, the paper used multivariate logistic regression to examine the effect of family planning advice and use of maternal health care utilization on contraceptive use in Bihar, India.

\section{Results}

Fig. 1 depicts that the knowledge of contraceptive methods in Bihar vary with the age of women and place of residence. A higher level of contraceptive knowledge is found among older age cohorts of 30-34. The analysis also shows similar results. Only $87 \%$ the younger women in the age group 15-19 were aware about any one method of contraception, which increased to $98 \%$ in the age group 35-39 and later on decrease in the old ages. Women residing in urban areas of Bihar were found having higher contraceptive knowledge than their rural 


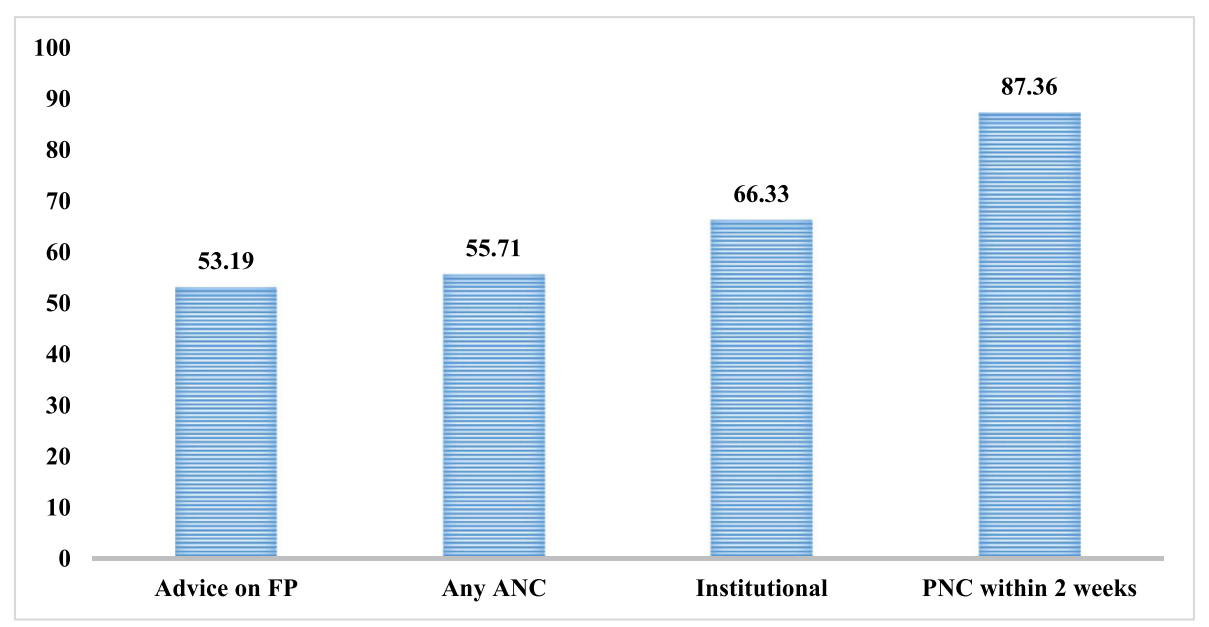

Fig. 2. Advice on FP and use of Maternal Health care utilization components in Bihar, 2015-16.

counterparts. [Fig. 1].

More than half of currently married women in Bihar received advice on family planning methods and also went for the any antenatal care visit. Sixty-six percent of the delivery are facility based and eightyseven percent women in Bihar received post-natal care [Fig. 2].

One-fourth of the currently married women is using contraceptive methods in Bihar which is relatively low (24\%) and below the national level of 54\% [NFHS, 2015-16]. Female sterilization is the most popular contraceptive method used in Bihar, used by $21 \%$ of currently married women, followed by condom (0.95) and pill (0.77). In Bihar, women are using more limiting methods (21\%) the spacing methods (only $3 \%$ ) [Fig. 3].

Almost one-fourth of the currently married women are using modern contraceptive methods and very few percent (1\%) women are using traditional methods of family planning. [Fig. 4].

Use of family planning methods by maternal health care factors according to background characteristic, Bihar India-2015-16, is presented in Table 1: Overall, nineteen percent women received advice on family planning, twenty percent women received any antenatal checkups, eighteen percent deliveries were conducted at health facility and twenty-three percent women were using family planning methods. Eighteen percent currently married women received family planning (FP) advice, utilized any antenatal checkups and delivered at health facility, were using modern contraception methods. Women receiving postnatal checkups within two weeks were more (twenty-one percent) using modern family planning methods. Age of the women comes up as an important factor for the use FP methods. The use of contraception increases with increase of age of the women till 35-39 age group, after which it declines. The rural-urban difference between use of family planning methods in Bihar is quite visible. Women living in urban area are using more contraceptive methods than their rural counterparts. Twenty-eight percent high caste women are using FP methods followed by OBC and SC/ST. FP users are more in Hindu religion than the nonHindus. In Bihar, FP users (both Modern and Traditional) have a positive relationship with wealth of the women. The use of family planning is more among secondary educated women compared to low and higher educated women.

Results from Binary Logistic Regression analysis of family planning use by maternal health care factors according to background characteristics, Bihar India-2015-16 are presented in Table 2. Study used two models for the analysis. In the first model, maternal health care utilization, age of the women, place of residence, education of the women, caste, religion and wealth of the women are included as predictor variables while in the second model, advice on family planning is included. The first model reflected that maternal health care utilization, age, residence, religion and wealth quintile are the significant predictors of contraception use but as we add variable advice on family planning in the second model, wealth of the women didn't play any

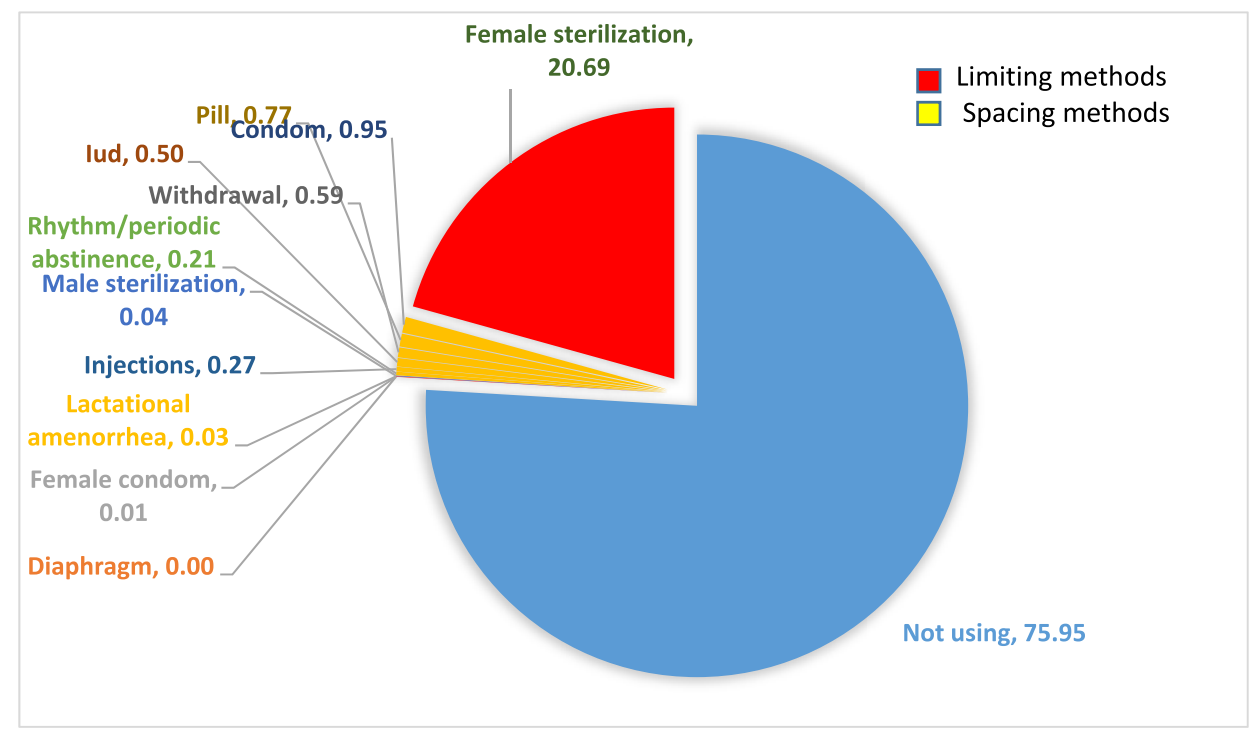

Fig. 3. Use of contraceptive methods among currently married women age 15-49 in Bihar, 2015-16. 


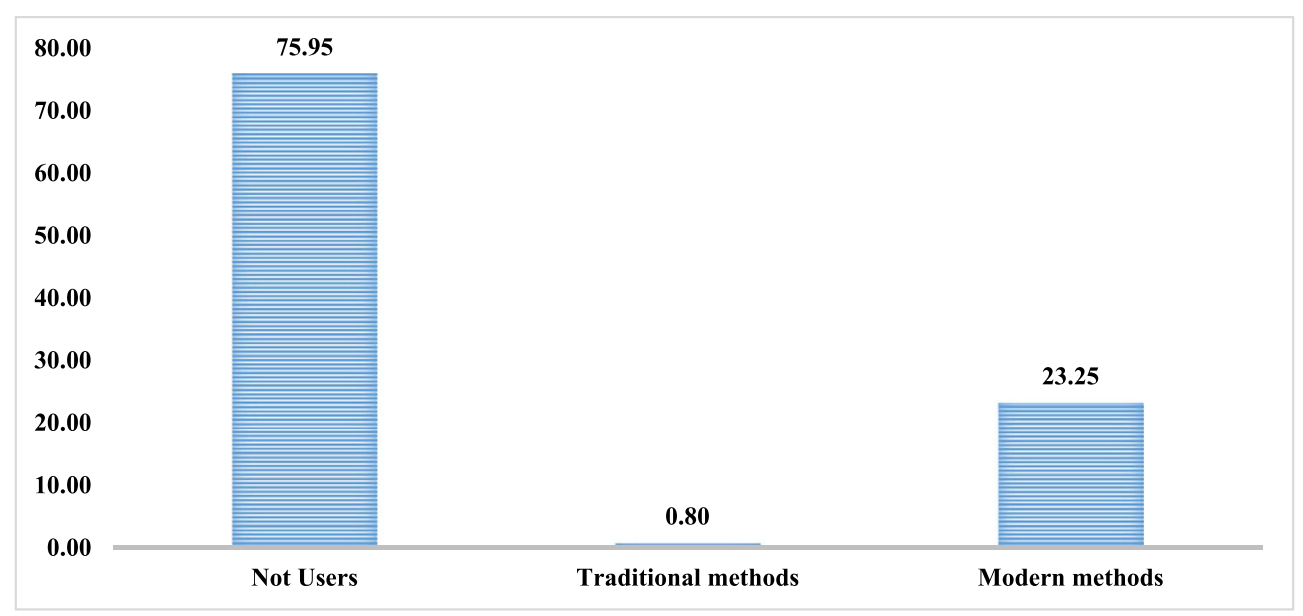

Fig. 4. Contraceptive use by type of methods among currently married women age 15-49 in Bihar, 2015-16.

Table 1

Use of family planning methods by maternal health care factors according to background characteristic, Bihar India-2015-16.

\begin{tabular}{|c|c|c|c|c|}
\hline Background indicators & Traditional & Modern & Users & $\mathrm{N}$ \\
\hline \multicolumn{5}{|l|}{ Advice $* * *$} \\
\hline No & 0.68 & 16.6 & 17.28 & 2488 \\
\hline Yes & 1.08 & 18.2 & 19.28 & 3061 \\
\hline \multicolumn{5}{|l|}{ ANC $* * *$} \\
\hline No & 0.40 & 15.22 & 15.62 & 6990 \\
\hline Yes & 1.36 & 18.16 & 19.52 & 9663 \\
\hline \multicolumn{5}{|l|}{ Delivery type ${ }^{* * *}$} \\
\hline Home & 0.51 & 15.62 & 16.13 & 5268 \\
\hline $\begin{array}{l}\text { Institutional } \\
\text { PNC** }\end{array}$ & 1.16 & 17.54 & 18.70 & 11,380 \\
\hline More than 2 weeks & 0.43 & 18.91 & 19.34 & 460 \\
\hline within 2 weeks & 2.01 & 20.59 & 22.6 & 3132 \\
\hline \multicolumn{5}{|l|}{ Age $\mathrm{e}^{* * *}$} \\
\hline $15-19$ & 0.17 & 1.63 & 1.80 & 2399 \\
\hline $20-24$ & 0.67 & 7.00 & 7.67 & 6528 \\
\hline $25-29$ & 1.05 & 21.32 & 22.37 & 7303 \\
\hline $30-34$ & 1.15 & 34.93 & 36.08 & 6003 \\
\hline $35-39$ & 1.34 & 38.72 & 40.06 & 5235 \\
\hline $40-44$ & 0.72 & 37.97 & 38.69 & 4043 \\
\hline $45-49$ & 0.49 & 33.4 & 33.89 & 3862 \\
\hline \multicolumn{5}{|l|}{ Residence ${ }^{* * *}$} \\
\hline Urban & 2.51 & 33.14 & 35.65 & 4336 \\
\hline Rural & 0.65 & 24.37 & 25.02 & 31,037 \\
\hline \multicolumn{5}{|l|}{ Education $* * *$} \\
\hline Illiterate & 0.60 & 25.67 & 26.27 & 19,505 \\
\hline Primary & 0.65 & 24.60 & 25.25 & 4020 \\
\hline Secondary & 1.16 & 25.73 & 26.89 & 10,325 \\
\hline Higher & 3.22 & 22.92 & 26.14 & 1523 \\
\hline \multicolumn{5}{|l|}{ Caste ${ }^{* * *}$} \\
\hline SC/ST & 0.45 & 22.86 & 23.31 & 8188 \\
\hline OBC & 0.97 & 26.18 & 27.15 & 21,235 \\
\hline Others & 1.16 & 27.13 & 28.29 & 5753 \\
\hline \multicolumn{5}{|l|}{ Religion*** } \\
\hline Hindu & 0.89 & 27.85 & 28.74 & 30,460 \\
\hline Non-Hindu & 0.85 & 10.54 & 11.39 & 4913 \\
\hline \multicolumn{5}{|l|}{ Wealth index $* * *$} \\
\hline Poorest & 0.48 & 22.19 & 22.67 & 17,297 \\
\hline Poorer & 0.74 & 25.68 & 26.42 & 8605 \\
\hline Middle & 1.18 & 29.25 & 30.43 & 5019 \\
\hline Richer & 1.89 & 32.01 & 33.90 & 3277 \\
\hline Richest & 3.74 & 37.11 & 40.85 & 1175 \\
\hline
\end{tabular}

Chi-square test $\mathrm{p}<0.01 * * * \mathrm{p}<0.05 * *$.

significant role for the use of contraception. Women who have received proper maternal health care (Any ANC + Institutional Delivery + Postnatal care), the likelihood is $43 \%$ more to use family planning methods. Maternal health care utilization has a significant impact on use of family planning methods. Advice on family planning
Table 2

Result from binary logistic regression analysis of family planning use by maternal health care factors according to background characteristics, Bihar India2015-16.

\begin{tabular}{|c|c|c|}
\hline Background indicators & Model 1 & Model 2 \\
\hline \multicolumn{3}{|l|}{ Advice } \\
\hline \multicolumn{3}{|l|}{$\mathrm{No}^{\circledast}$} \\
\hline Yes & & $1.073(0.902-1.276)$ \\
\hline \multicolumn{3}{|l|}{ MH utilization } \\
\hline \multicolumn{3}{|l|}{ Not Received $\mathrm{MH}^{\circledast}$} \\
\hline Received MH & $1.592^{* * *}(1.4-1.81)$ & $1.436^{* * *}(1.187-1.736)$ \\
\hline \multicolumn{3}{|l|}{ Age } \\
\hline \multicolumn{3}{|l|}{$15-19^{\circledR}$} \\
\hline $20-24$ & $2.146^{* * *}(1.314-3.504)$ & $2.37 * *(1.017-5.52)$ \\
\hline $25-29$ & $5.774 * * *(3.565-9.352)$ & $6.132^{* * *}(2.663-14.117)$ \\
\hline $30-34$ & $8.473^{* * *}(5.211-13.776)$ & $9.433^{* * *}(4.075-21.838)$ \\
\hline $35-39$ & $8.479 * * *(5.149-13.963)$ & $9.242 * * *(3.899-21.909)$ \\
\hline $40-44$ & $6.785^{* * *}(3.955-11.639)$ & $9.422^{* * *}(3.79-23.427)$ \\
\hline $45-49$ & $6.303^{* * *}(3.277-12.121)$ & $2.675(0.629-11.374)$ \\
\hline \multicolumn{3}{|l|}{ Residence } \\
\hline \multicolumn{3}{|l|}{ Urban ${ }^{\circledast}$} \\
\hline Rural & $0.739^{* * *}(0.617-0.886)$ & $0.697 * *(0.494-0.984)$ \\
\hline \multicolumn{3}{|l|}{ Education } \\
\hline \multicolumn{3}{|l|}{ Illiterate $^{\circledast}$} \\
\hline Primary & $1.083(0.923-1.272)$ & $1.186(0.912-1.543)$ \\
\hline Secondary & $1.017(0.88-1.174)$ & $1.003(0.789-1.275)$ \\
\hline Higher & $1.167(0.854-1.594)$ & $1.032(0.546-1.949)$ \\
\hline \multicolumn{3}{|l|}{ Caste } \\
\hline \multicolumn{3}{|l|}{$\mathrm{SC} / \mathrm{ST}^{\circledast}$} \\
\hline ОВС & $1.097(0.976-1.233)$ & $1.052(0.868-1.274)$ \\
\hline Others & $1.164(0.964-1.406)$ & $0.966(0.689-1.355)$ \\
\hline \multicolumn{3}{|l|}{ Religion } \\
\hline \multicolumn{3}{|l|}{ Hindu ${ }^{\circledast}$} \\
\hline Non-Hindu & $0.299 * * *(0.249-0.359)$ & $0.349 * * *(0.252-0.482)$ \\
\hline \multicolumn{3}{|l|}{ Wealth index } \\
\hline \multicolumn{3}{|l|}{ Poorest $^{\oplus}$} \\
\hline Poorer & $1.182 * *(1.04-1.343)$ & $1.074(0.867-1.33)$ \\
\hline Middle & $1.335^{* * *}(1.112-1.601)$ & $1.118(0.81-1.543)$ \\
\hline Richer & $1.497 * * *(1.17-1.915)$ & $1.439(0.899-2.304)$ \\
\hline Richest & $1.509 * *(0.993-2.294)$ & $1.446(0.553-3.782)$ \\
\hline
\end{tabular}

Note: ${ }^{\circledR}$ refers Reference Category, $\mathrm{p}<0.10^{*}, \mathrm{p}<0.05^{* *}, \mathrm{p}<0.01^{* * *}$.

plays an important role in the use of contraception, however results are not statistically significant. However, age and wealth of the women shows positive relationship with use of contraception methods. As age and wealth of currently married women increase, the use of family planning services also increases. The women living in rural areas are thirty-one percent less likely to use of family planning methods than urban ones. Non-Hindu women are sixty-six percent less likely to use family planning methods than the Hindu counterparts. Interestingly, results suggest that advice on family planning didn't have much effect 
on birth control in Bihar.

\section{Discussion}

The study is focused to understand the impact of family planning advice and maternal health care utilization on contraceptive usage in Bihar based on the sample of currently married women. The percentage of currently married women using contraception in Bihar remains at a much lower level than the national average. The factors like age, belonging to high caste, hailing from richer wealth quantiles and education were positively associated with women using family planning methods in Bihar. ${ }^{23}$ The socioeconomic differentials in contraceptive use reflect that unequal distribution of resources and contraceptives still exist in Bihar. ${ }^{24}$ It emerges that younger women ${ }^{15-19}$ are less aware and less likely to use contraceptives than older women (35-39) in Bihar. This finding goes in tune with an earlier study which states that younger women do not use contraceptives before their first pregnancy. ${ }^{25}$ There was a significant rural-urban divide in use of family planning methods which presumably depicts a situation where awareness and services of family planning methods are still not reaching to the women belonging to rural areas. ${ }^{26}$ The results from regression model I depict that maternal health care utilization, age, residence, religion and wealth quintile were the significant predictors of contraception use among women in Bihar. While the importance of wealth disappeared when advice on family planning is added in model II. Higher preponderance of contraceptive use was found among women receiving proper maternal health care were, depicting that maternal health care utilization as an important predictor of use of family planning methods among women in Bihar. ${ }^{7}$ Moreover, the advice given to women on family planning does not emerged as an important factor influencing contraceptive use in case of Bihar. Thus, it is pretty much evident from the results that maternal health care utilization effects and positively influences the contraceptive use among women in Bihar, whereas the advice on family planning lacked any statistical significance in relation to contraceptive use.

\section{Conclusion}

It is essential to learn that there is a considerable difference in the awareness and the use of contraception among the women. Though the knowledge of family planning methods is universal among women and more than half of the women received advice on family planning methods, but only one-fourth of the currently married women are using family planning methods in Bihar. The possible reason behind the low efficiency of family planning advice in limiting birth rates in Bihar could be because of lack of women literacy, low autonomy, highly male-dominated patriarchy system and other cultural effects. Maternal health care utilization is more effective in increasing the current use of family planning which could be because of contact with the healthcare services which have a strong influence in accepting family planning services. The study calls for strengthening the outreach for encouraging female education, enhancing their employment and empowering women so that they are able enough to taking sensible decisions in matters relating to personal health and fertility choices. More needs to be done to support the need for effective maternal health care utilization to increase the use of contraception in Bihar. Thus, efforts are required to ensure that currently married women across socio-economic backgrounds have an equal opportunity to received maternal health services. The study also opens scope for further understanding the variations of contraceptive use according to autonomy levels, male involvement in the family planning decision-making process in Bihar.

Limitations: This study has few limitations as well. First, the study is based on a cross sectional data, hence the cause and effect relationship between the predictors and the independent variables could not be established. Second, it used restricted sample of currently married women in Bihar only; therefore, the findings of the study cannot be applied or generalized for India or other states.

\section{Declaration of competing interest}

None.

\section{References}

1. Nation United. Department of economic and social affairs PD trends in contraceptive use worldwide 2015. Contraception. 2015:1-70.

2. McCleary-Sills J, McGonagle A, Malhotra. A Women's Demand for Reproductive Control: Understanding and Addressing Gender Barriers Cent Res Women. 2012; 2012.

3. Ahmed S, Li Q, Liu L, Tsui AO. Maternal deaths averted by contraceptive use: an analysis of 172 countries. Lancet. 2012;380(9837):111-125.

4. United Nation, Department of Economic and Social Affairs PD. Trends in contraceptive use Worldwide 2015. Contraception. 2015:1-70.

5. Dockalova B, Lau K, Barclay H, Marshall A. Sustainable Development Goals and Family Planning 2020. 2016; 2016.

6. Nikiéma B, Beninguisse G, Haggerty JL. Providing information on pregnancy complications during antenatal visits: unmet educational needs in sub-Saharan Africa. Health Pol Plann. 2009;24(5):367-376.

7. Yadav D, Dhillon P. Assessing the impact of family planning advice on unmet need and contraceptive use among currently married women in Uttar Pradesh, India. PloS One. 2015;10(3):1-16.

8. Pembe AB, Urassa DP, Carlstedt A, Lindmark G, Nyström L, Darj E. Rural Tanzanian women's awareness of danger signs of obstetric complications. BMC Pregnancy Childbirth. 2009;9(1):12.

9. Levitt C, Shaw E, Wong S, et al. Systematic review of the literature on postpartum care: selected contraception methods, postpartum Papanicolaou test, and rubella immunization. Birth. 2004;31(3):203-212.

10. Zerai A, Tsui AO. The relationship between prenatal care and subsequent modern contraceptive use in Bolivia, Egypt and Thailand. Afr J Reprod Health. 2001:5(2):68-82.

11. Seiber EE, Hotchkiss DR, Rous JJ, Berruti AA. Maternal and child health and family planning service utilization in Guatemala: implications for service integration. Soc Sci Med. 2005;61(2):279-291.

12. Ahmed S, Mosley WH. Simultaneity in the use of maternal-child health care and contraceptives: evidence from developing countries. Demography. 2002;39(1):75-93.

13. O World Health Organization. Reproductive Health Strategy to Accelerate Progress towards the Attainment of International Development Goals and Targets. Geneva: World Health Organization; 2004.

14. Matthews Z, Mahendra S, Kilaru A, Ganapathy S. Antenatal care, care-seeking and morbidity in rural Karnataka, India: results of a prospective study. Asia Pac Popul J. 2001;16(2):11-28.

15. Sugathan KS, Mishra VK, Retherford RD. Promoting Institutional Deliveries in Rural India: The Role of Antenatal-Care Services. 2001; 2001.

16. Birungi H, Onyango-Ouma W. Acceptability and Sustainability of the WHO Focused Antenatal Care Package in Kenya. 2006; 2006

17. Sines E, Syed U, Wall S, Worley H. Postnatal care: a critical opportunity to save mothers and newborns. Pol Perspect Nborn Health 2007:1-7.

18. Anwar AT, Killewo J, Chowdhury MK, Dasgupta S. Bangladesh: Inequalities in Utilization of Maternal Health Care Services-Evidence from Matlab Reach Poor with Heal Nutr Popul Serv Work what Doesn't, why. Washington DC World Bank; 2005

19. Jat TR, Ng N, San Sebastian M. Factors affecting the use of maternal health services in Madhya Pradesh state of India: a multilevel analysis. Int $J$ Equity Health. 2011;10(1):59

20. Singh A, Padmadas SS, Mishra US, Pallikadavath S, Johnson FA, Matthews Z. Socioeconomic inequalities in the use of postnatal care in India. PloS One. 2012;7(5):e37037.

21. Lopez LM, Grey TW, Hiller JE, Chen M. Education for contraceptive use by women after childbirth. Cochrane Database Syst Rev. 2015;7.

22. Indian Institute for Population Sciences (IIPS) and ICF. Ministry of Health and Family Welfare. National Family Health Survey (NFHS-4), 2015-16: India. Int Inst Popul Sci ICF; 2017:1-192http://rchiips.org/nfhs/NFHS-4Reports/India.pdf.

23. Jejeebhoy SJ, Prakash R, Acharya R, Singh SK. Meeting Contraceptive Needs : LongTerm Associations of the PRACHAR Project with Married Women'S Awareness and Behavior in Bihar. vol. 41. 2015; 20153.

24. Kumar A, Singh A. Trends and determinants of unmet need for family planning in Bihar (India): evidence from. Natl Fam Health Surv. 2013;3(2):157-163.

25. Jejeebhoy SJ, Santhya KG, Zavier AJF, Jejeebhoy SJ, Santhya KG, Zavier AJF Women in India demand for contraception to delay first pregnancy among young married in all access use of contraceptives. 2019;45(2):183-201.

26. Pal A, Yadav J,.S, Singh KJ. Factors associated with unmet need of family planning in Bihar, India: a spatial and multilevel analysis. Int J Reprod Contracept Obstet Gynecol. 2018;7(9):3638. 